\title{
The ISKDC classification and a new semiquantitative classification for predicting outcomes of Henoch-Schonlein
} purpura nephritis

\section{Koskela, Mikael}

2017-07

Koskela , M , Ylinen , E , Ukonmaanaho, E-M , Autio-Harmainen , H , Heikkilä , P , Lohi , J , Jauhola , O, Ronkainen, J , Jahnukainen, T \& Nuutinen, M 2017, ' The ISKDC classification and a new semiquantitative classification for predicting outcomes of Henoch-Schonlein purpura nephritis ', Pediatric Nephrology , vol. 32 , no. 7 , pp. 1201-1209 . https://doi.org/10.1007/s00467-017-3608-5

http://hdl.handle.net/10138/237008

https://doi.org/10.1007/s00467-017-3608-5

publishedVersion

Downloaded from Helda, University of Helsinki institutional repository.

This is an electronic reprint of the original article.

This reprint may differ from the original in pagination and typographic detail.

Please cite the original version. 


\title{
The ISKDC classification and a new semiquantitative classification for predicting outcomes of Henoch-Schönlein purpura nephritis
}

\author{
Mikael Koskela $^{1}$ - Elisa Ylinen ${ }^{1}$ Elli-Maija Ukonmaanaho ${ }^{2}$. \\ Helena Autio-Harmainen ${ }^{3}$ • Päivi Heikkilä ${ }^{4}$. Jouko Lohi ${ }^{4}$ • Outi Jauhola ${ }^{5}$. \\ Jaana Ronkainen $^{6}$ • Timo Jahnukainen ${ }^{1}$ - Matti Nuutinen ${ }^{2,7}$
}

Received: 22 September 2016 / Revised: 29 December 2016/Accepted: 19 January 2017 /Published online: 14 February 2017 (C) IPNA 2017

\begin{abstract}
Background Histological findings from primary kidney biopsies were correlated with patient outcomes in a national cohort of paediatric Henoch-Schönlein nephritis (HSN) patients.

Methods Primary kidney biopsies from $53 \mathrm{HSN}$ patients were re-evaluated using the ISKDC (International Study of Kidney Disease in Children) classification and a modified semiquantitative classification (SQC) that scores renal findings and also takes into account activity, chronicity and tubulointerstitial indices. The ISKDC and SQC classifications were evaluated comparatively in four outcome groups: no signs of renal disease (outcome $\mathrm{A}, n=27$ ), minor urinary abnormalities (outcome $\mathrm{B}, n=18$ ), active renal disease (outcome $\mathrm{C}, n=3$ ) and
\end{abstract}

Electronic supplementary material The online version of this article (doi:10.1007/s00467-017-3608-5) contains supplementary material, which is available to authorized users.

Mikael Koskela

mikael.koskela@helsinki.fi

1 Department of Pediatric Nephrology and Transplantation, Children's Hospital, Helsinki University Hospital and University of Helsinki, PO Box 281, 00029 Helsinki, Finland

2 Department of Children and Adolescents, Oulu University Hospital, Oulu, Finland

3 Medical Research Center Oulu and Department of Pathology, Oulu University Hospital, Oulu, Finland

4 Department of Pathology, Helsinki University Hospital, Helsinki, Finland

5 Department of Pediatrics, Hyvinkää Hospital, Hyvinkää, Finland

6 Oulu City Health Care Centre, Oulu, Finland

7 Research Unit for Pediatrics, Dermatology, Clinical Genetics, Obstetrics and Gynecology (PEDEGO Research Unit), Medical Reasearch Center Oulu (MRC Oulu), Oulu, Finland renal insufficiency, end-stage renal disease or succumbed due to HSN (outcome $\mathrm{D}, n=5$ ). For the receiver operating characteristic and logistic regression analyses, outcomes A and B were considered to be favourable and outcomes $\mathrm{C}$ and $\mathrm{D}$ to be unfavourable. The median follow-up time was 7.3 years.

Results The patients with an unfavourable outcome $(\mathrm{C}$ and D), considered together due to low patient numbers, had significantly higher total biopsy SQC scores and activity indices than those who had a favourable one (groups A and B). The chronicity and tubulointerstitial indices differed significantly only between group $\mathrm{C}+\mathrm{D}$ and group $\mathrm{A}$. The difference in areas under the curve between the total biopsy SQC scores and ISKDC findings was $0.15[p=0.04$, normal-based $95 \%$ confidence interval (CI) 0.007-0.29, bias-controlled 95\% CI -0.004 to 0.28 ].

Conclusions Our results suggest that the modified SQC is more sensitive than ISKDC classification for predicting the outcome in HSN cases.

Keywords Children $\cdot$ Glomerulonephritis $\cdot$ Histology $\cdot$ Renal biopsy $\cdot$ Semiquantitative $\cdot$ Vasculitis

\section{Introduction}

Henoch-Schönlein purpura (HSP) is the most common form of vasculitis in children [1]. Although the prognosis is generally good, severe nephritis (HSN) remains the major cause of morbidity and mortality among children with HSP [2]. In a systematic review of 12 studies involving 1133 unselected patients with HSP, $34.2 \%$ of the patients were found to have had renal involvement [3]. The outcome and severity of HSN is difficult to predict due to the wide variability in its signs and symptoms [4]. A kidney biopsy has therefore remained the 
gold standard for evaluating the severity of HSN and the associated prognosis.

The classical grading system for renal biopsies in cases of HSN is the International Study of Kidney Disease in Children (ISKDC) classification [5], which is based mainly on the presence and number of affected glomeruli. However, the ISKDC classification has been criticized on the grounds that it ignores tubulointerstitial and vascular changes $[4,6]$. This has led to the introduction of various semiquantitative classifications. We have developed a practical and sensitive histological semiquantitative classification (SQC), as used by Ronkainen et al. for the evaluation of immunoglobulin A ( $\operatorname{IgA}$ ) nephropathy [7].

The aim of the study reported here was to evaluate the feasibility of the modified SQC in cases of HSN. To this end, we compared the ISKDC and SQC classifications for their ability to predict the clinical outcome in a cohort of HSN patients. Clinical variables at the time of the biopsy were also evaluated relative to patient outcomes.

\section{Methods}

The study population consisted of patients recruited for our previous HSN projects at Helsinki University Hospital (20002010) and Oulu University Hospital (1985-2005) and for a nationwide HSN cohort study (1999-2006) [8] (Electronic Supplementary Material Table S1). A total of 53 patients (24 boys, 29 girls) with biopsy-proven HSN and aged $<17$ years at the time of diagnosis were identified from our patient register. Their medical histories and laboratory results were retrieved and analysed retrospectively from the onset of HSP until the latest control visit, with a focus on evaluating the clinical course of the disease over time in terms of symptoms, laboratory findings, treatment administered and resolution of symptoms achieved. We also collected information on the duration of time elapsing from the first symptoms to the first biopsy and from the biopsy to the initiation of possible treatment. Renal function was evaluated by calculating the estimated glomerular filtration rate (eGFR) using the Bedside Schwartz equation [9] or the Chronic Kidney Disease Epidemiology Collaboration (CKD-EPI) equation for patients aged $>18$ years [10]. Proteinuria was defined as urine protein excretion of $>200 \mathrm{mg} / 24 \mathrm{~h}$ measured from 24 -h urine collection (dU-Prot) or calculated from a spot urine sample using estimated protein excretion [11]. Haematuria was defined as $>5$ red blood cells (RBCs)/high-power field, $>20$ RBCs/10E6/ $\mathrm{L}$, or a positive dipstick test (+ to +++ ).

The outcome for each patient was assessed at the time of the last control visit, using a modified version of the grading system reported by Goldstein et al. [12] and Ronkainen et al. [13]. The clinical outcome was graded as: $A=$ no signs of renal disease in laboratory tests and normal blood pressure;
$\mathrm{B}=$ minor urinary abnormalities (microscopic haematuria and/or protein/creatinine ratio of $21-200 \mathrm{mg} / \mathrm{mmol}$ ) or antiproteinuric/anti-hypertensive medication in use, normal blood pressure and GFR; $C=$ protein/creatinine ratio of $\geq 200 \mathrm{mg} /$ mmol or hypertension [blood pressure (BP) $>160 /$ $95 \mathrm{mmHg}$ ] or immunosuppressive medication in use; $\mathrm{D}=$ reduced renal function $\left(\mathrm{GFR}<60 \mathrm{ml} / \mathrm{min} / 1.73 \mathrm{~m}^{2}\right)$. Grades A and $\mathrm{B}$ were both considered to be favourable outcomes but were analysed separately while grades $\mathrm{C}$ and $\mathrm{D}$ were considered to be unfavourable outcomes and were analysed together as group $\mathrm{C}+\mathrm{D}$ due to the small number of patients in each group ( 3 and 5 patients in groups $\mathrm{C}$ and $\mathrm{D}$, respectively).

The clinical characteristics at the time of the biopsy in all patients and in different outcome groups separately are presented in Table 1. At the end of the follow-up (median 7.3 years), there were 27 patients $(51 \%)$ in outcome group A, $18(34 \%)$ in group B, three (6\%) in outcome group C and five $(9 \%)$ in outcome group D. One patient in group $\mathrm{C}$ was hypertensive despite being treated with two anti-hypertensive drugs, one patient had nephrotic-range proteinuria and one was receiving cyclosporine (CyA) due to persistent proteinuria. One patient in group D had died of an HSN-related hypertensive crisis [14], two had undergone kidney transplantations (14.4 and 5.7 years after the initial diagnosis) and two had developed renal insufficiency (estimated GFR 37 and $45 \mathrm{ml} / \mathrm{min} / 1.73 \mathrm{~m}^{2}$ ).

Of the 53 patients enrolled in the study, 38 (72\%) had received immunosuppressive treatment based on kidney biopsy findings. Briefly, most patients with ISKDC grade $\geq$ III and some patients with ISKDC grade II were treated with methylprednisolone pulses followed by oral prednisolone, CyA, cyclophosphamide, azathioprine or mycophenolate mofetil in various combinations. Angiotensin-converting enzyme inhibitors (ACEs) and angiotensin-receptor blockers (ARBs) were typically used as additional treatments to control proteinuria. Some patients with ISKDC grade II and with ISKDC grade III and non-nephrotic proteinuria received only ACEs and/or ARBs. All patients with an ISKDC grade higher than III had received immunosuppressive treatment. The ISKDC grades refer to the re-evaluation, but the treatment decisions were based on the original biopsy report. Oral prednisolone or prednisone for extrarenal symptoms was prescribed in 26 cases (49\%) and ACEs and/or ARBs in 45 cases (85\%).

All of the kidney biopsy samples were re-analysed by experienced renal pathologists (P.H. and J.L. at Helsinki University Hospital and H.A.-H. at Oulu University Hospital), who were blinded to the patients' histories. The biopsies were then classified using both the ISKDC classification (Table 2) and the modified SQC (Table 3 ) in which the glomerular, tubular, interstitial and vascular findings were scored separately, giving a maximum (total biopsy) score of 26 points. The SQC can also be divided into an activity index (maximum 9 points), chronicity index (maximum 16 points) 
Table 1 Clinical characteristics of the patients at the time of the biopsy

\begin{tabular}{|c|c|c|c|c|c|}
\hline Clinical characteristics & All patients $(n=53)$ & Outcome group A $(n=27)$ & Outcome group B $(n=18)$ & $\begin{array}{l}\text { Combined outcome } \\
\text { group } \mathrm{C}+\mathrm{D}(n=8)\end{array}$ & $p$ value $^{\mathrm{a}}$ \\
\hline Gender (female:male) & $29: 24$ & $13: 14$ & $12: 6$ & $4: 4$ & $0.49^{\mathrm{b}}$ \\
\hline Age (years) & $10.2 \pm 3.3$ & $9.3 \pm 3.3$ & $11.0 \pm 3.2$ & $11.8 \pm 2.3$ & $0.073^{\mathrm{c}}$ \\
\hline Follow-up (years) & $7.3(5.4-9.5)$ & $6.6(5.2-8.6)$ & $7.0(5.1-9.4)$ & $10.2(7.3-12.5)$ & $0.22^{\mathrm{c}}$ \\
\hline Plasma creatinine $(\mu \mathrm{mol} / \mathrm{L})$ & $50.0(43.0-56.0)$ & $45.0(40.0-54.5)$ & $52.5(45.0-58.0)$ & $54.0(49.5-83.0)$ & $0.094^{\mathrm{c}}$ \\
\hline $\mathrm{eGFR}\left(\mathrm{ml} / \mathrm{min} / 1.73 \mathrm{~m}^{2}\right)$ & $106 \pm 27$ & $111 \pm 24$ & $104 \pm 27$ & $95 \pm 33$ & $0.36^{\mathrm{c}}$ \\
\hline dU-Prot (g/day) & $2.6(1.1-6.3)$ & $2.6(1.1-5.4)$ & $2.1(0.3-4.1)$ & $10.2(5.5-12.9)$ & $0.018^{\mathrm{c}}$ \\
\hline Plasma albumin (g/L) & $29.3(23.7-38.3)$ & $33.0(25.2-38.0)$ & $32.9(28.0-40.0)$ & $20.5(18.8-29.0)$ & $0.12^{\mathrm{c}}$ \\
\hline Patients with hematuria & $100 \%$ & $100 \%$ & $100 \%$ & $100 \%$ & \\
\hline Systolic BP (mmHg) & $116.8 \pm 13.8$ & $116.5 \pm 15.2$ & $110.8 \pm 8.2$ & $130.1 \pm 8.7$ & $0.002^{\mathrm{c}}$ \\
\hline Diastolic BP (mmHg) & $68.1 \pm 12.9$ & $68.7 \pm 13.8$ & $65.4 \pm 11.5$ & $71.8 \pm 12.4$ & $0.36^{\mathrm{c}}$ \\
\hline $\begin{array}{l}\text { Time from onset of nephritis to } \\
\text { biopsy (days) }\end{array}$ & $57(28-106)$ & $56(32-87)$ & $75(35-106)$ & $29(18-141)$ & $0.36^{\mathrm{c}}$ \\
\hline Time from biopsy to treatment (days) & $8(2-23)$ & $7(3-15)$ & $11(8-32)$ & $7(2-23)$ & $0.49^{\mathrm{c}}$ \\
\hline $\begin{array}{l}\text { Treatment of nephritis with steroids or } \\
\text { other immunosuppressives }\end{array}$ & $38(72 \%)$ & $19(70 \%)$ & $11(61 \%)$ & $8(100 \%)$ & $0.12^{\mathrm{b}}$ \\
\hline
\end{tabular}

Values in table are presented as a number with/without the percentage in parenthesis, the mean \pm standard deviation or the median with the interquartile range in parenthesis, as appropriate

eGFR, Estimated glomerular filtration rate; dU-Prot, 24-h urine protein excretion; BP, blood pressure

${ }^{\text {a }}$ Comparison between outcome groups A, B and combined group C + D

${ }^{\mathrm{b}}$ Fisher's exact test

${ }^{\mathrm{c}}$ Kruskal-Wallis test

and focal or diffuse mesangial proliferation ( 0 points for focal, 1 point for diffuse). In addition, a tubulointerstitial index (combining all tubular and interstitial parameters from the SQC, including both active and chronic changes, maximum 5 points) was calculated. Inter-rater reliability (IRR) was calculated from a randomly chosen subset of ten biopsies which were evaluated and scored with SQC by renal pathologists.

\section{Statistical analyses}

The statistical analyses were performed using IBM SPSS for Windows, version 22 (IBM Corp, Armonk, NY). In addition, areas under the curve (AUC) were compared

Table 2 The grading system of the International Study of Kidney Disease in Children classification for renal biopsies in cases of Henoch-Schönlein nephritis

ISKDC grade Description

\begin{tabular}{ll}
\hline Grade I & Minimal changes \\
Grade II & Mesangial proliferation \\
Grade III & Crescents $<50 \%$ of the glomeruli; A: Focal, B: Diffuse \\
Grade IV & Crescents $50-75 \%$ of the glomeruli; A: Focal, B: Diffuse \\
Grade V & Crescents $>75 \%$ of the glomeruli \\
Grade VI & Membranoproliferative glomerulonephritis \\
\hline
\end{tabular}

ISKDC, The International Study of Kidney Disease in Children using Stata 12.1 (StataCorp LP, College Station, TX) in the form of the Stata user-written module [15]. A total of 5000 bootstrap resamples were drawn to estimate the $95 \%$ confidence intervals $(95 \% \mathrm{CI})$ of the AUC for histological classification systems and their AUC difference. For the purposes of AUC analysis, outcome grades A and B were coded as non-diseased and grades $\mathrm{C}$ and $\mathrm{D}$ as diseased. Youden indices (optimal cut-off points when sensitivity and specificity are given equal weight) were calculated from receiver operating characteristic (ROC) curves [16]. Histological classifications were also compared using logistic regression and reported in terms of odds ratios, profile likelihood CIs and Akaike Information Criterion (AIC) (lower AIC values indicate better model fitting). IRR was assessed using two-way mixed, absolute agreement intra-class correlation coefficients (ICC) . Cut-offs for ICC are as follows: poor for $<0.4$, fair for $0.4-0.59$, good for 0.6-0.74 and excellent for 0.75-1.0 [17]. Continuous variables with a normal distribution are reported as means with standard deviation, and data that did not show a normal distribution were reported as medians with their interquartile range (IQR). Categorical variables are presented as numbers and percentages. Missing values are treated as missing in the analyses. Comparisons of multiple groups were performed with the KruskalWallis test, and if a difference was found among the groups tested, a post hoc analysis was performed with 
Table 3 Histological scoring system of the modified semiquantitative classification for renal biopsies in cases of Henoch-Schönlein nephritis

\begin{tabular}{|c|c|c|}
\hline Modified SQC & Description & Score \\
\hline \multicolumn{3}{|l|}{ Glomerular changes } \\
\hline Lobulation & Active & $0-1^{\mathrm{a}}$ \\
\hline Mesangial proliferation & Active & $0-1^{\mathrm{a}}$ \\
\hline \multicolumn{3}{|l|}{ Crescents } \\
\hline Cellular & Active & $0-3^{\mathrm{b}}$ \\
\hline Fibrous & Chronic & $0-3^{\mathrm{b}}$ \\
\hline Adhesions & Chronic & $0-3^{\mathrm{b}}$ \\
\hline Fibrinous thrombosis & Active & $0-3^{\mathrm{b}}$ \\
\hline Global sclerosis & Chronic & $0-3^{\mathrm{b}}$ \\
\hline Segmental sclerosis & Chronic & $0-2^{\mathrm{c}}$ \\
\hline \multicolumn{3}{|l|}{ Tubular changes } \\
\hline Thickening of the basement membrane & Chronic & $0-1^{\mathrm{a}}$ \\
\hline Complete atrophy & Chronic & $0-1^{\mathrm{a}}$ \\
\hline Tubular dilatation & Active & $0-1^{\mathrm{a}}$ \\
\hline \multicolumn{3}{|l|}{ Interstitial changes } \\
\hline Fibrosis & Chronic & $0-1^{\mathrm{a}}$ \\
\hline Inflammation OR periglomerular inflammation & Chronic & $0-1^{\mathrm{a}}$ \\
\hline \multicolumn{3}{|l|}{ Capillary changes } \\
\hline Arteriosclerosis OR arterial inflammation & Chronic & $0-1^{\mathrm{a}}$ \\
\hline Focal or diffuse mesangial proliferation & & 0 for focal, 1 for diffuse \\
\hline \multicolumn{3}{|l|}{ SQC, Semiquantitative classification } \\
\hline \multicolumn{3}{|l|}{${ }^{\mathrm{a}} 0=$ absent; $1=$ present } \\
\hline \multicolumn{3}{|c|}{$\begin{array}{l}{ }^{\mathrm{b}} 0=0 \% \text { of glomeruli affected; } 1=0-5 \% \text { of glomeruli affected; } 2=5-10 \% \text { of glomeruli affected; } 3=>10 \% \text { of } \\
\text { glomeruli affected }\end{array}$} \\
\hline
\end{tabular}

the Mann-Whitney $U$ test using the Bonferroni correction and exact $p$ values. Comparisons of categorical variables were performed with Fisher's exact test and also presented with relative risk (RR) and 95\% CI data. Statistical significance was set at $p<0.05$.

\section{Results}

The distribution of the ISKDC grades and SQC scores with respect to the four outcome groups are presented in Tables 4 and 5 , respectively. The total biopsy score $(p=$ $0.001)$, activity index $(p=0.003)$, chronicity index $(p=$ $0.030)$ and tubulointerstitial index $(p=0.022)$ differed significantly between the three outcome groups $(\mathrm{A}, \mathrm{B}, \mathrm{C}+$
D; Table 5; Fig. 1). According to the post hoc analysis, the total biopsy score and activity index were significantly higher in outcome group $\mathrm{C}+\mathrm{D}$ than in group $\mathrm{A}$ (Bonferroni adjusted $p<0.001$ for the total biopsy score and $p=0.001$ for the activity index) or group $B$ (Bonferroni adjusted $p=0.004$ for the total biopsy score and $p=0.008$ for the activity index). The corresponding differences in the chronicity and tubulointerstitial indices were significant only between group $\mathrm{C}+\mathrm{D}$ and group $\mathrm{A}$ (Bonferroni adjusted $p=0.009$ for chronicity index and $p=0.013$ for tubulointerstitial index), but not between group $\mathrm{C}+\mathrm{D}$ and group $\mathrm{B}$ (Bonferroni adjusted $p=0.37$ for chronicity index and $p=0.33$ for tubulointerstitial index). There were no statistically significant differences in any of the four biopsy categories of SQC between

Table 4 International Study of Kidney Disease in Children(ISKDC) grades in all patients and separately according to long-term renal outcomes

\begin{tabular}{llllll}
\hline $\begin{array}{l}\text { ISKDC } \\
\text { grades }\end{array}$ & $\begin{array}{l}\text { All patients } \\
(n=53)\end{array}$ & $\begin{array}{l}\text { Outcome } \\
\text { group A }(n=27)\end{array}$ & $\begin{array}{l}\text { Outcome } \\
\text { group B }(n=18)\end{array}$ & $\begin{array}{l}\text { Outcome } \\
\text { group C (n=3) }\end{array}$ & $\begin{array}{l}\text { Outcome } \\
\text { group D (n=5) }\end{array}$ \\
\hline II & 18 & 10 & 8 & 0 & 0 \\
III & 32 & 16 & 10 & 3 & 3 \\
IV & 2 & 1 & 0 & 0 & 1 \\
V & 1 & 0 & 0 & 0 & 1 \\
\hline
\end{tabular}


Table 5 Semiquantitative classification (SQC) scores in all patients and separately according to long-term renal outcomes

\begin{tabular}{lllll}
\hline SQC categories & All patients $(n=53)$ & Outcome group A $(n=27)$ & Outcome group B $(n=18)$ & $\begin{array}{l}\text { Combined outcome } \\
\text { group C }+\mathrm{D}(n=8)\end{array}$ \\
\hline Total biopsy score & $7.0(4.0-11.0)$ & $6.0(4.0-8.5)$ & $6.0(4.0-9.0)$ & $13.0(11.0-14.5)$ \\
Activity index & $4.0(2.0-6.0)$ & $3.0(2.0-4.0)$ & $3.0(2.0-5.0)$ & $7.5(6.0-8.0)$ \\
Chronicity index & $3.0(0-4.0)$ & $2.0(0-3.0)$ & $2.5(0-5.0)$ & $4.0(3.5-5.5)$ \\
Tubulointerstitial index & $0(0-1.0)$ & $0(0-1.0)$ & $0(0-1.0)$ & $0.001^{\mathrm{b}}$ \\
\hline
\end{tabular}

${ }^{\text {a }}$ Comparison was between outcome groups $\mathrm{A}, \mathrm{B}$ and combined group $\mathrm{C}+\mathrm{D}$

${ }^{\mathrm{b}}$ Kruskal-Wallis test

outcome groups A and B (Bonferroni adjusted $p>0.99$ for the total biopsy score, $p>0.99$ for the activity index, $p>0.99$ for the chronicity index and $p=0.71$ for the tubulointerstitial index). The median number of glomeruli was 22 (IQR $12-31)$.
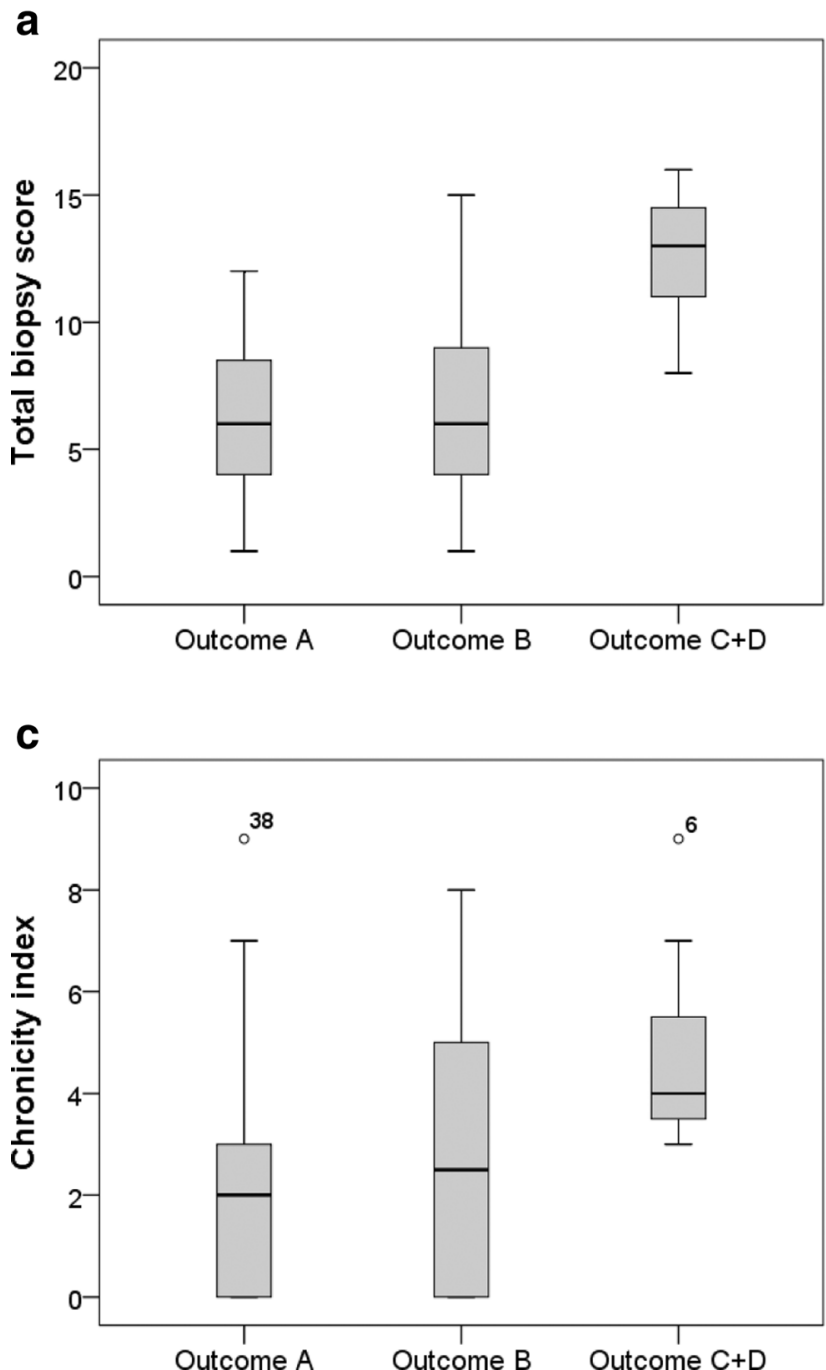

Eighteen biopsies (34\%) were classified as ISKDC grade II, 32 biopsies (60\%) as ISKDC grade III, two biopsies (4\%) as ISKDC grade IV and one biopsy (2\%) as ISKDC grade V. None of the patients with ISKDC grade II and six of the 32 (19\%) patients with ISKDC grade III had an unfavourable

b

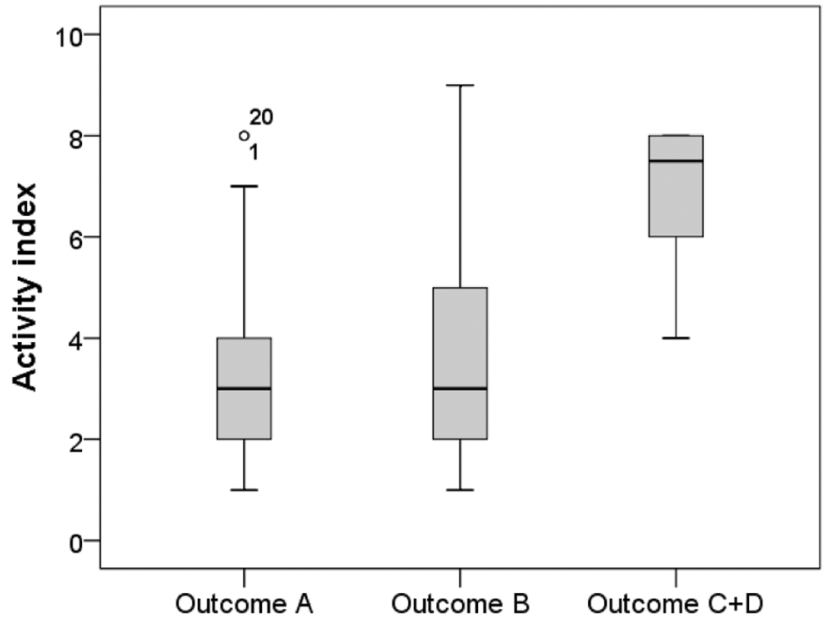

d

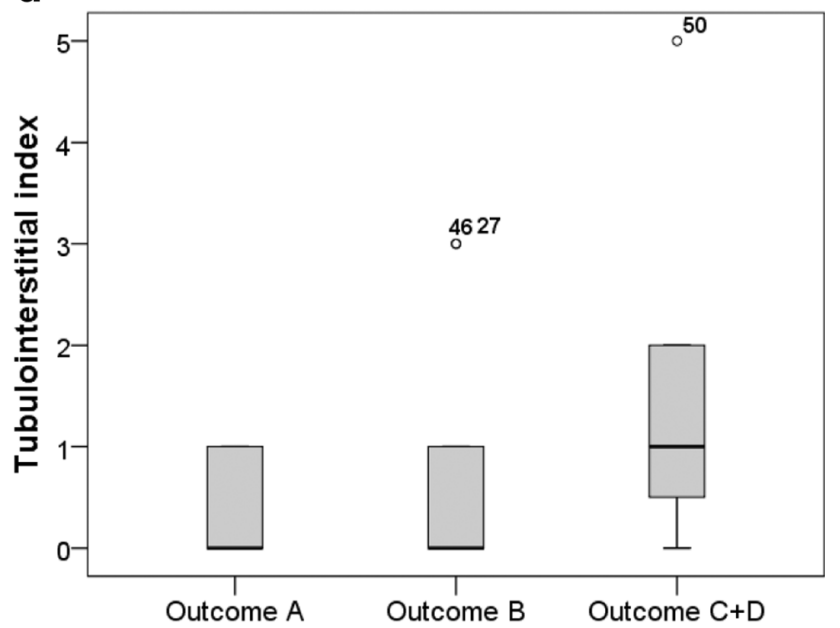

Fig. 1 Box-plots of all semiquantitative classification biopsy categories with respect to the three outcome groups: a total biopsy score, $\mathbf{b}$ activity index, $\mathbf{c}$ chronicity index, $\mathbf{d}$ tubulointerstitial index 


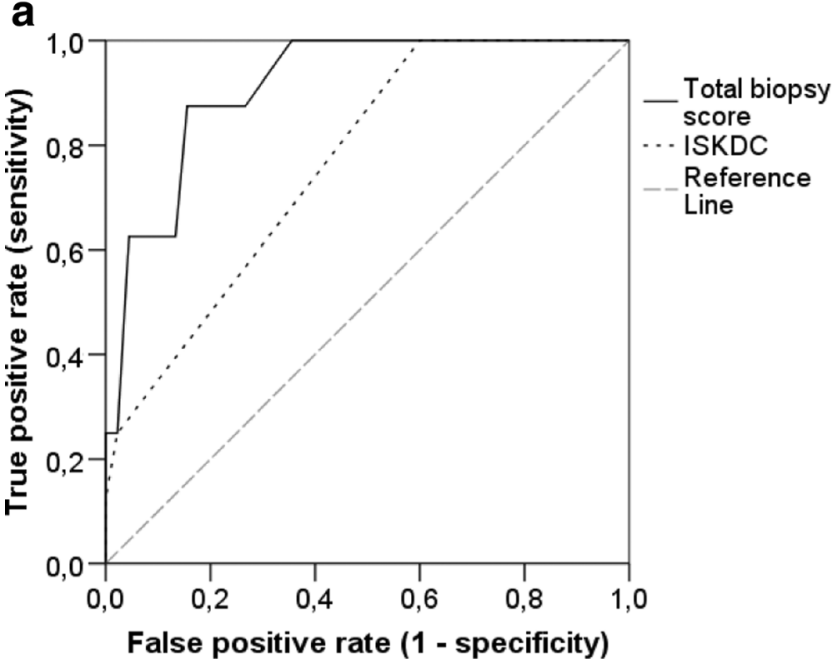

Fig. 2 Receiver operating characteristic (ROC) curves for the total biopsy score, International Study of Kidney Disease in Children (ISKDC) classification, activity index and chronicity index. For the purpose of the ROC analyses outcome groups A and B were coded as nondiseased and $\mathrm{C}$ and $\mathrm{D}$ as diseased. Areas under the curve (AUC) for the total biopsy score, ISKDC classification, activity index and chronicity index were 0.912 [95\% confidence interval (CI) $0.824-1.0$ ], 0.765 (95\% CI $0.607-0.923), 0.878$ (95\% CI $0.780-0.975)$ and 0.776 (95\% CI 0.647-0.906), respectively. The AUC difference between the total

outcome. Of the two patients with ISKDC grade IV, one had a favourable outcome and the other an unfavourable one. The only patient with ISKCD grade $\mathrm{V}$ had an unfavourable outcome.

The true positive rate (sensitivity) and false positive rate (1 - specificity) of the biopsy classifications were compared using ROC curve analyses and by calculating the respective AUC values (Fig. 2). The total biopsy score had the largest AUC, 0.912 (95\% CI 0.824-1.0), followed by the activity index, 0.878 (95\% CI $0.780-0.975$ ), the chronicity index, 0.776 (95\% CI $0.647-0.906)$ and the ISKDC, 0.765 (95\% CI 0.607-0.923). The AUC difference between the total biopsy score and ISKDC classification was $0.15(p=0.04$, normal-based $95 \%$ CI $0.007-$ 0.29 , bias-corrected $95 \% \mathrm{CI}-0.004$ to 0.28 ). The Youden index for the total biopsy score was 0.72 , and the corresponding cut-off point was 10.5 . When this cut-off point was applied to the patient outcomes, seven of the 14 $(50 \%)$ patients with a total biopsy score of $\geq 11$ had an unfavourable outcome, while only one of $39(3 \%)$ patients with a total biopsy score of $\leq 10$ had an unfavourable outcome (7/14 vs. 1/39; RR 19.5, 95\% CI 2.6-144.7, Fisher's exact test $p<0.001)$. For ISKDC, the Youden index was 0.40 , and the corresponding cut-off point was 2.5. When this cut-off point was used, eight of the 35 patients with ISKDC grade III or higher $(23 \%)$ and zero of the 18 of the patients with ISKDC grade II or lower ( $0 \%$; 0.5 was added to all cells to calculate the RR) had an b

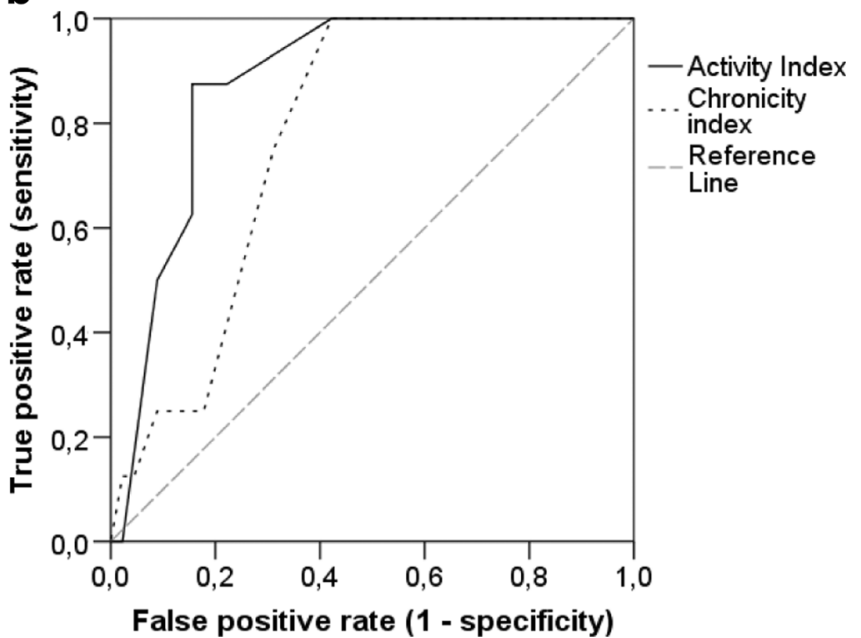

biopsy score and ISKDC classification was 0.147 (normal-based $95 \%$ CI $0.007-0.287$, bias-corrected $95 \%$ CI -0.004 to 0.281 ), that between the activity index and ISKDC classification was 0.112 (normal-based $95 \% \mathrm{CI}-0.021$ to 0.246 , bias-corrected $95 \% \mathrm{CI}-0.028$ to 0.241 ) and that between the chronicity index and ISKDC classification was 0.011 (normal-based $95 \%$ CI -0.162 to 0.184 , bias-corrected 95\% -0.168 to 0.178 ). a ROC curves for the total biopsy score and ISKDC classification, b ROC curves for the activity index and chronicity index

unfavourable outcome (8/35 vs. 0/18; RR 9.0, 95\% CI $0.5-147.2$, Fisher's exact test $p=0.040)$. We also compared the biopsy classifications using univariate logistic regression (Table 6), in which the fit of the model was tested by calculating AIC values; the total biopsy score of the SQC had the lowest value, 30.8, while that for the ISKDC was 38.8. The IRR of the SQC classification, when assessed with ICC, was 0.43 for single measures and 0.61 for average measures.

There were statistically significant differences in urine protein excretion between the outcome groups $(p=0.018)$ at the time of the biopsy (Table 1; Fig. 3). Post hoc pairwise comparisons showed that dU-Prot at the time of the first biopsy was significantly higher in combined group $\mathrm{C}+\mathrm{D}$ than that in group A (Bonferroni adjusted $p=0.036$ ) or $\mathrm{B}$ (Bonferroni

Table 6 Comparisons between the International Study of Kidney Disease in Children (ISKDC) classification and Semiquantitative Classification (SQC) scoring systems using univariate logistic regression analysis

\begin{tabular}{llll}
\hline $\begin{array}{l}\text { Classification } \\
\text { systems }\end{array}$ & $\begin{array}{l}\text { Akaike information } \\
\text { criterion }\end{array}$ & $\begin{array}{l}\text { Odds } \\
\text { ratio }\end{array}$ & $\begin{array}{l}95 \% \text { Confidence } \\
\text { interval }\end{array}$ \\
\hline $\begin{array}{l}\text { SQC-Total biopsy } \\
\quad 30 \text { - }\end{array}$ & 30.8 & 1.72 & $1.28-2.73$ \\
SQC-Activity index & 35.1 & 1.94 & $1.33-3.28$ \\
SQC-Chronicity index & 43.4 & 1.42 & $1.06-1.99$ \\
ISKDC classification & 38.8 & 11.32 & $2.2-217.24$ \\
\hline
\end{tabular}


a

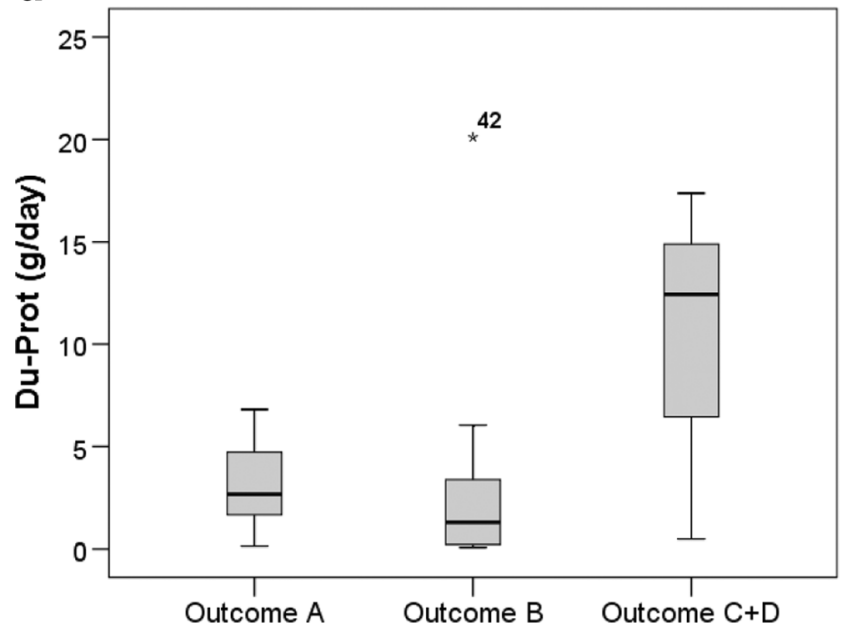

b

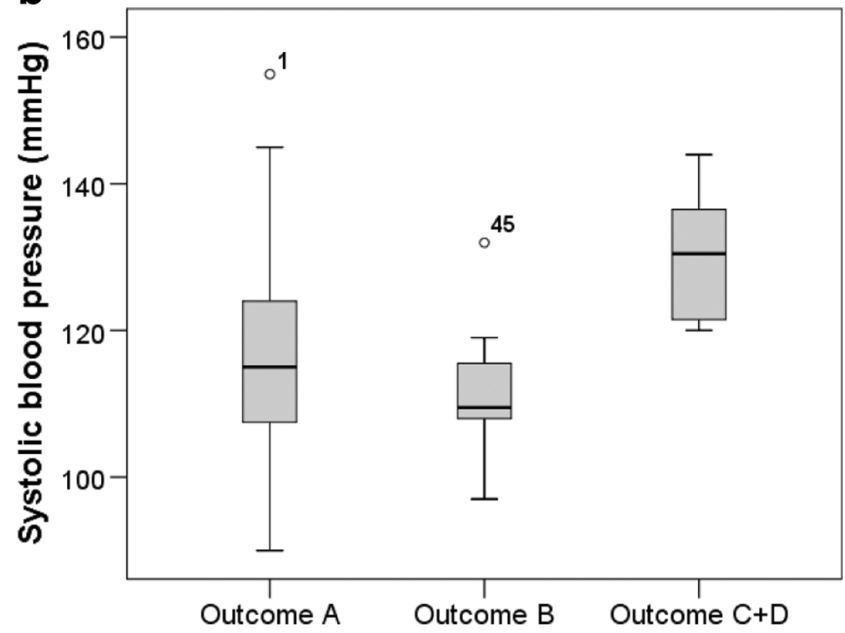

Fig. 3 a Box-plot of 24-h urine protein excretion at the time of the biopsy in relation to the three outcome groups, $\mathbf{b}$ box-plot of systolic blood pressure at the time of the biopsy in relation to the three outcome groups. $d U$-Prot $24-\mathrm{h}$ Urine protein excretion

adjusted $p=0.026$ ), whereas there was no difference in $\mathrm{dU}$ Prot between groups A and B (Bonferroni adjusted $p>0.99$ ). Also, systolic blood pressure at the time of the biopsy was higher in group $\mathrm{C}+\mathrm{D}$ than in group $\mathrm{A}$ (Bonferroni adjusted $p=0.025$ ) or $\mathrm{B}$ (Bonferroni adjusted $p<0.001$ ) (Table 1 ; Fig. 3). Again, groups A and B had a similar systolic blood pressure (Bonferroni adjusted $p=0.64$ ). No statistically significant differences between the three outcome groups were found in any of the other laboratory or demographic parameters studied here (Table 1).

\section{Discussion}

The correlation between primary kidney biopsy findings and patient outcome was evaluated here in a nationwide cohort of paediatric HSN patients. Re-evaluation of the biopsy samples using both the ISKDC classification and a modified SQC scoring system showed the SQC to be more coherent and more sensitive in terms of predicting patient outcomes. In addition, proteinuria and systolic blood pressure at the time of diagnosis were found to correlate with the outcome. The proportion of patients with a poor outcome in our series was eight in $53(15 \%)$ patients which is slightly lower than that reported in other surveys with similar or shorter follow-up times $[18,19]$. One explanation of this difference may be that most of the patients in our cohort had received immunosuppressive and/or antiproteinuric treatment for nephritis.

The ISKDC classification was published in 1977 and has been used widely as a grading system for HSN and IgA nephropathy. It has nevertheless been criticized for taking only mesangial proliferation and the percentage of crescentic glomeruli into consideration and ignoring other glomerular and tubulointerstitial parameters $[4,6]$. We have previously shown in an HSP cohort that patients with a low (grades I and II)
ISKDC grade in their first biopsy may have an unfavourable long-term outcome [13]. This suggests that evaluation of the activity and chronicity components separately is important as early treatment is warranted in patients whose biopsy shows mainly active changes while a primary biopsy showing predominantly chronic changes does not justify prolonged, aggressive immunosuppressive treatment. The influence of tubulointerstitial changes on clinical severity in patients with HSN has also been addressed [20-22], and reports from several authors have shown a discrepancy in the correlation between ISKDC grades and the outcome [13, 19, 23, 24]. Other semiquantitative classifications evaluating multiple glomerular, tubulointerstitial and vascular parameters in addition to our SQC have also been introduced for the histological evaluation of HSN [20, 22, 25-27], but they are not widely used in clinical practice. The Oxford classification [28] was published in 2009 as a histological classification for IgA nephropathy, a disease which is histologically similar to HSN [29]. To our knowledge, there have been no studies of the feasibility of using the Oxford classification in the case of children with HSP, although Kim et al. did suggest that it could be used for predicting the long-term outcome in adult HSP patients [30]. The main differences between the Oxford classification and the SQC concern the number of histological parameters evaluated, as the Oxford classification considers four variables and the SQC takes into account a total of 14 variables. There are also some pathophysiological differences between HSP and IgA nephropathy. For example, onset of the disease is typically more acute in HSP than in IgA nephropathy [31], emphasizing the need for analysing the activity and chronicity components separately.

We adopted here a modified version of the classification used in our earlier work in which we found that the chronicity index and the total biopsy score were the best histological factors for predicting the outcome of patients with childhood 
IgA nephropathy [7]. For the purposes of the present study, the classification was expanded to include evaluations of mesangial proliferation, lobulation and focal or diffuse mesangial proliferation and applied to a cohort of HSN patients. According to our analyses, the total biopsy score and activity index were the best factors for predicting the outcome. Both variables also tended to be better than ISKDC grades for predicting patient outcome when expressed in terms of AUC and AIC values. The importance of active lesions is understandable, since we were analysing primary kidney biopsies. Other studies have also shown a correlation between the acuity score of the primary biopsy and clinical severity [20] and reported that active lesions are predictors of a poor outcome [18]. The total biopsy score obtained in the SQC was also useful for differentiating patients with favourable and unfavourable outcomes, since those with a total biopsy score of $\leq 10$ points usually had a good prognosis [1/39 patients had an unfavourable outcome (3\%)], while those with a score of $\geq 11$ had a greater risk of renal impairment [7/14 patients had an unfavourable outcome (50\%)].

Several authors have concluded that the long-term outcome of HSN is determined by the severity of renal involvement at the onset of the disease $[3,12,13]$, a notion which is also supported by our findings as the patients with an unfavourable outcome had significantly higher dU-Prot than those with a favourable outcome. In addition, long-term follow-up studies of the prognosis for HSN have shown that clinical recovery does not inevitably mean a favourable long-term outcome [12, $13,32]$. It is therefore possible that clinical deterioration will occur even in our cohort of HSN patients in the future, since the median follow-up time was only 7.3 years. Our patients with an unfavourable outcome also had higher systolic blood pressure at the time of the biopsy than those with a favourable outcome, whereas other studies have failed to find initial hypertension to be a predictor of a poor outcome in multivariate regression analysis [24, 32]. One possible explanation for the different results is that we analysed the absolute blood pressure figures and did not categorize the patients into those with or without hypertension.

There are a number of limitations to our findings. One, and probably the most important, is the variability in treatment within our cohort, which is undoubtedly a confounding factor. It is also possible that the active nature of the treatment may have hampered the overall prognostic value of the kidney biopsies $[19,33]$. Thirty-eight of our patients $(72 \%)$ had received immunosuppressive treatment for nephritis and 45 (85\%) had received ACE/ARB medication for hypertension and/or to control proteinuria. On the other hand, all eight patients with an unfavourable outcome had received immunosuppressive treatment and seven (88\%) had received ACE/ ARB medication at some point in the treatment of their disease, although the immunosuppressive treatments used and their timing and duration varied between patients. It is therefore difficult to draw any conclusions on the influence of treatment on patient outcome. Twenty-six patients had also received oral prednisone or prednisolone for extrarenal symptoms before the biopsy, but we have previously shown that early treatment with low-dose steroids does not prevent the development of nephritis in HSP [34] and does not have an effect on the frequency or timing of the nephritis [35]. Also, even though there is bias due to the treatment, it does not hamper the evaluation and comparison of the two classifications since the scorings were performed from the same biopsies obtained from the same patients and were then compared against each other in their ability to predict the outcome. Another limitation of this work is that we did not take into account any confounding factors in the ROC curve and logistic regression analyses. This is due to the small sample size, and especially the small number of patients with an unfavourable outcome which might bias logistic regression results [36].

In conclusion, although a kidney biopsy is mandatory for the diagnosis of HSN, its value as a predictor of the outcome is dependent on many clinical variables, and also on the classification used. Our suggestion is that a semiquantitative classification including activity and chronicity indices should be introduced into clinical practice. For this purpose, larger prospective studies on the prognostic value of kidney biopsies for the treatment of HSN patients are needed in order to evaluate SQC and other scoring systems.

Acknowledgements The authors wish to thank Jesper Kivelä and Mitja Lääperi for assistance in the statistical analyses.

\section{Compliance with ethical standards}

Funding This work was supported by a grant to M.K. from the Alma and K.A. Snellman Foundation, Oulu, Finland and from the Foundation of Paediatric Research and salary to M.K. from Competitive State Research Financing of the Expert Responsibility area of Oulu University Hospital.

Conflict of interest The authors declare that they have no conflict of interest.

\section{References}

1. Gardner-Medwin JM, Dolezalova P, Cummins C, Southwood TR (2002) Incidence of Henoch-SchonleinSchönlein purpura, Kawasaki disease, and rare vasculitides in children of different ethnic origins. Lancet 360:1197-1202

2. Saulsbury FT (2007) Clinical update: Henoch-SchonleinSchönlein purpura. Lancet 369:976-978

3. Narchi H (2005) Risk of long term renal impairment and duration of follow up recommended for Henoch-SchonleinSchönlein purpura with normal or minimal urinary findings: a systematic review. Arch Dis Child 90:916-920 
4. Davin JC (2011) Henoch-SchonleinSchönlein purpura nephritis: pathophysiology, treatment, and future strategy. Clin J Am Soc Nephrol 6:679-689

5. Counahan R, Winterborn MH, White RH, Heaton JM, Meadow SR, Bluett NH, Swetschin H, Cameron JS, Chantler C (1977) Prognosis of Henoch-SchonleinSchönlein nephritis in children. Br Med J 2:11-14

6. Davin JC, Coppo R (2013) Pitfalls in recommending evidencebased guidelines for a protean disease like HenochSchonleinSchönlein purpura nephritis. Pediatr Nephrol 28:18971903

7. Ronkainen J, Ala-Houhala M, Autio-Harmainen H, Jahnukainen T, Koskimies O, Merenmies J, Mustonen J, Ormala T, Turtinen J, Nuutinen M (2006) Long-term outcome 19 years after childhood IgA nephritis: a retrospective cohort study. Pediatr Nephrol 21: 1266-1273

8. Jauhola O, Ronkainen J, Autio-Harmainen H, Koskimies O, AlaHouhala M, Arikoski P, Holtta T, Jahnukainen T, Rajantie J, Ormala T, Nuutinen M (2011) Cyclosporine A vs. methylprednisolone for Henoch-SchonleinSchönlein nephritis: a randomized trial. Pediatr Nephrol 26:2159-2166

9. Schwartz GJ, Munoz A, Schneider MF, Mak RH, Kaskel F, Warady BA, Furth SL (2009) New equations to estimate GFR in children with CKD. J Am Soc Nephrol 20:629-637

10. Levey AS, Stevens LA, Schmid CH, Zhang YL, 3rd Castro AF, Feldman HI, Kusek JW, Eggers P, Van Lente F, Greene T, Coresh J, CKD-EPI (Chronic Kidney Disease Epidemiology Collaboration) (2009) A new equation to estimate glomerular filtration rate. Ann Intern Med 150:604-612

11. Kidney Disease: Improving Global Outcomes (KDIGO) CKD Work Group (2013) KDIGO 2012 Clinical practice guideline for the evaluation and management of chronic kidney disease. Kidney Int Suppl 3:1-150. http://kdigo.org/home/guidelines/ckdevaluation-management/

12. Goldstein AR, White RH, Akuse R, Chantler C (1992) Long-term follow-up of childhood Henoch-SchonleinSchönlein nephritis. Lancet 339:280-282

13. Ronkainen J, Nuutinen M, Koskimies O (2002) The adult kidney 24 years after childhood purpura: a retrospective cohort study. Lancet 360:666-670

14. Nuutinen M, Lautala P, Remes M, Uhari M (2000) Nephrectomy in severe hypertension. Clin Nephrol 54:342-346

15. Pepe MS, Longton G, Janes H (2009) Estimation and comparison of receiver operating characteristic curves. Stata J 9:1-16

16. Clayton P. CUTPT: Stata module for empirical estimation of cutpoint for a diagnostic test. https://Ideas.Repec.Org/C/Boc/ Bocode/S457719.Html. Accessed May 2016

17. Cicchetti D (1994) Guidelines, criteria, and rules of thumb for evaluating normed and standardized assessment instruments in psychology. Psychol Assess 6:284-290

18. Edstrom Halling S, Soderberg MP, Berg UB (2010) Predictors of outcome in Henoch-SchonleinSchönlein nephritis. Pediatr Nephrol 25:1101-1108

19. Ronkainen J, Ala-Houhala M, Huttunen NP, Jahnukainen T, Koskimies O, Ormala T, Nuutinen M (2003) Outcome of Henoch-SchonleinSchönlein nephritis with nephrotic-range proteinuria. Clin Nephrol 60:80-84

20. Foster BJ, Bernard C, Drummond KN, Sharma AK (2000) Effective therapy for severe Henoch-SchonleinSchönlein purpura nephritis with prednisone and azathioprine: a clinical and histopathologic study. J Pediatr 136:370-375

21. Lim BJ, Shin JI, Choi SE, Rhim H, Lee JS, Kim PK, Jeong HJ, Kim JH (2016) The significance of tubulointerstitial lesions in childhood Henoch-SchonleinSchönlein nephritis. Pediatr Nephrol 31:20872093
22. Pillebout E, Thervet E, Hill G, Alberti C, Vanhille P, Nochy D (2002) Henoch-SchonleinSchönlein purpura in adults: outcome and prognostic factors. J Am Soc Nephrol 13:1271-1278

23. Wakaki H, Ishikura K, Hataya H, Hamasaki Y, Sakai T, Yata N, Kaneko T, Honda M (2011) Henoch-SchonleinSchönlein purpura nephritis with nephrotic state in children: predictors of poor outcomes. Pediatr Nephrol 26:921-925

24. Coppo R, Andrulli S, Amore A, Gianoglio B, Conti G, Peruzzi L, Locatelli F, Cagnoli L (2006) Predictors of outcome in HenochSchonleinSchönlein nephritis in children and adults. Am J Kidney Dis 47:993-1003

25. Niaudet P, Habib R (1998) Methylprednisolone pulse therapy in the treatment of severe forms of Henoch-SchonleinSchönlein purpura nephritis. Pediatr Nephrol 12:238-243

26. Kawasaki Y, Suzuki J, Suzuki H (2004) Efficacy of methylprednisolone and urokinase pulse therapy combined with or without cyclophosphamide in severe Henoch-SchonleinSchönlein nephritis: a clinical and histopathological study. Nephrol Dial Transplant 19: 858-864

27. Szeto CC, Choi PC, To KF, Li PK, Hui J, Chow KM, Leung CB, Lui SF, Mac-Moune Lai F (2001) Grading of acute and chronic renal lesions in Henoch-SchonleinSchönlein purpura. Mod Pathol 14:635-640

28. Working Group of the International IgA Nephropathy Network and the Renal Pathology Society, Roberts IS, Cook HT, Troyanov S, Alpers CE, Amore A, Barratt J, Berthoux F, Bonsib S, Bruijn JA, Cattran DC, Coppo R, D'Agati V, D'Amico G, Emancipator S, Emma F, Feehally J, Ferrario F, Fervenza FC, Florquin S, Fogo A, Geddes CC, Groene HJ, Haas M, Herzenberg AM, Hill PA, Hogg RJ, Hsu SI, Jennette JC, Joh K, Julian BA, Kawamura T, Lai FM, Li LS, Li PK, Liu ZH, Mackinnon B, Mezzano S, Schena FP, Tomino Y, Walker PD, Wang H, Weening JJ, Yoshikawa N, Zhang H (2009) The oxford classification of IgA nephropathy: pathology definitions, correlations, and reproducibility. Kidney Int 76:546-556

29. Pohl M (2015) Henoch-SchonleinSchönlein purpura nephritis. Pediatr Nephrol 30:245-252

30. Kim CH, Lim BJ, Bae YS, Kwon YE, Kim YL, Nam KH, Park KS, An SY, Koo HM, Doh FM, Lee MJ, Oh HJ, Yoo TH, Kang SW, Choi KH, Jeong HJ, Han SH (2014) Using the oxford classification of IgA nephropathy to predict long-term outcomes of HenochSchonleinSchönlein purpura nephritis in adults. Mod Pathol 27: 972-982

31. Davin JC, Ten Berge IJ, Weening JJ (2001) What is the difference between IgA nephropathy and Henoch-SchonleinSchönlein purpura nephritis? Kidney Int 59:823-834

32. Scharer K, Krmar R, Querfeld U, Ruder H, Waldherr R, Schaefer F (1999) Clinical outcome of Henoch-SchonleinSchönlein purpura nephritis in children. Pediatr Nephrol 13:816-823

33. Davin JC, Coppo R (2014) Henoch-SchonleinSchönlein purpura nephritis in children. Nat Rev Nephrol 10:563-573

34. Ronkainen J, Koskimies O, Ala-Houhala M, Antikainen M, Merenmies J, Rajantie J, Ormala T, Turtinen J, Nuutinen M (2006) Early prednisone therapy in Henoch-SchonleinSchönlein purpura: a randomized, double-blind, placebo-controlled trial. J Pediatr 149:241-247

35. Jauhola O, Ronkainen J, Koskimies O, Ala-Houhala M, Arikoski P, Holtta T, Jahnukainen T, Rajantie J, Ormala T, Turtinen J, Nuutinen M (2010) Renal manifestations of Henoch-SchonleinSchönlein purpura in a 6-month prospective study of 223 children. Arch Dis Child 95:877-882

36. Vittinghoff E, McCulloch CE (2007) Relaxing the rule of ten events per variable in logistic and Cox regression. Am J Epidemiol 165: $710-718$ 